\title{
Research on the Key Techniques of Rotary Bearing Man-hour Ration Management System
}

\author{
Yongming Wang ${ }^{*}$, Shuai Xia ${ }^{1}$ \\ ${ }^{1}$ School of Mechanical Engineering, Anhui University of Technology, Maanshan, Anhui Province, P.R. China. \\ *Corresponding author. Tel.: (86)0555-2316517; email: wym_ahut@163.com \\ Manuscript submitted May 5, 2014; accepted September 17, 2014.
}

\begin{abstract}
Man-hour ration is an important work in process planning, it influences on the production cost and production plan. According to the practical requirements of rotary bearing manufacturing enterprise, a function framework of man-hour ration management system is proposed in the paper. Some key techniques are discussed, involving UML modeling, man-hour calculation method based on the general procedure, automatic generation and print of man-hour report. On this basis, a man-hour ration management system of rotary bearing is developed by using object-oriented programming method and SQL Sever database technology. Finally, an application case is given, which is easy to operate, and the man-hour calculation is fast and accurate, the generated man-hour report is unified and standardize.
\end{abstract}

Key words: Rotary bearing, man-hour ration, unified modeling language, general procedure, man-hour report.

\section{Introduction}

Man-hour ration [1], [2] is an important and basic work for the modern enterprise management. With the development of the technology, it is necessary to improve the quality and efficiency of the man-hour ration by using computer aided technologies.

At present, the traditional method of man-hour ration mainly relies on the relevant process manual or timesheets, and the level of man-hour ration depends on the technologist's working experience and proficiency. This traditional kind of man-hour calculation method is low efficiency and poor accuracy. Computer aided man-hour ration [3] can significantly improve the efficiency of man-hour ration, which is an important part of CAPP system. But the existing commercial management software of the man-hour ration is mostly less of pertinence.

According to the practical requirements of rotary bearing manufacturing enterprise, the paper brings forward the overall framework of man-hour ration management system and discusses some key technologies of software development, involving UML modeling, man-hour calculation method, automatic generation and print of man-hour report, in order to improve the promptness and accuracy of man-hour calculation management.

\section{The Requirement Analysis}

Various series rotary bearing products have the similar structures, only some specific parameters of each type are different, so their machining processes are basically the same. So we can prepare the universal process planning template of the series products in advance, and use CAPP technology [4] to generate the process models automatically. 
Combined with the actual needs of some rotary bearing manufacturing enterprise, man-hour ration management system should meet the following requirement:

Support Single Row Ball Rotary Bearing: There are two standard for the single row ball rotary bearing, JB/T10839-2008 and JB/T2300-1999 [5], [6], the man-hour ration management system should support them.

Provide Interface with CAPP System: The man-hour ration management system should be able to provide a seamless integration interface with the rotary bearing CAPP system, i.e. the man-hour quota management module is added to the rotary support CAPP system through the interface technology. Unlike the existing commercial software, the man-hour ration management system should be able to realize seamless integration with the rotary bearing CAPP system and it can calculate the process time automatically based on the universal process planning model in CAPP system.

Requirement of Man-hour Ration: System should be able to satisfy the calculation, query and modify of man-hour ration for inner and outer parts of different rotary bearing products. It should also provide the function of generate and print the summary table and detailed statement of planning man-hour automatically.

Database Functions: According to user requirements, the database can be added, deleted and modified.

User Permissions Management Functions: Assign user permissions according to different roles, and provide the operating permissions for the corresponding module.

\section{Overall Framework of the System}

Base on the above requirement analysis, the paper puts forward the overall framework of rotary bearing man-hour ration management system, which is shown in Fig. 1. There are seven modules, which are summarized below.

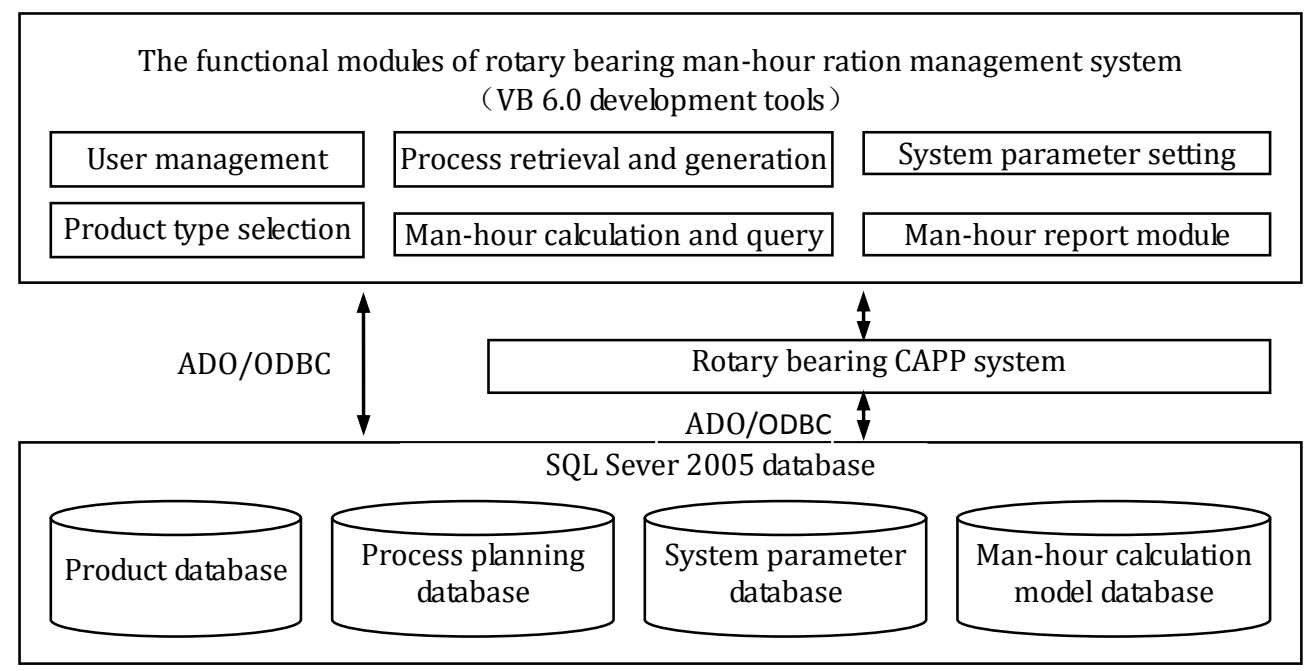

Fig. 1. The overall frame of rotary bearing man-hour ration management system.

User management module: This module includes some functions such as set user permissions, delete users, modify password, register users, and logout users, etc. It assigns user permissions according to his roles. It can automatic recognize his operating permission according to user login, and provide corresponding functional module for the user to use.

Product type selection module: The users can choose the product series, type, transmission and installation groove of rotary bearing. According to the above retrieval conditions, the system will query the corresponding products processing information automatically based on product database.

Process retrieval and generation module: according to the product type, transmission type and installation groove which be chosen by users, the system automatically retrieves the process planning library and calls the corresponding general process template, what's more according to the information of technological parameters 
of parts, the system automatically modify technical schedule, generate technical schedule of the parts, and provide data parameter the for the subsequent calculation and query of man-hour ration.

Man-hour calculation and query module: This module can automatically calculate the machining man-hour of rotary bearing parts according to the process planning generated in process retrieval and generation module. This module can also be run independently to complete the query function of man-hour quota information of specified type parts.

System parameter setting module: The users can be authorized to edit and change the correction factor and default value of system parameters which involved in the calculation of man-hour, such as surface roughness coefficient, material coefficient of correction coefficient, skill levels of workers, machine tool correction coefficient and so on.

Man-hour report module: This module provides the function of a variety of man-hour statistics report, it can automatically generates a variety of summary tables and detailed statements of planning man-hour, besides, it also can provide the function of print preview and output.

Database: By using SQL Sever 2005, this system establishes many databases, mainly includes product database, process planning database, system parameter database and man-hour calculation model database, etc. Product database is used to store basic parameter information of various type of single row ball style rotary bearing. Process planning database is mainly used to store the process and step information of general process template. System parameter database is mainly used to store the correction factor and default value of system parameters which involved in the calculation of man-hour, its value can be changed in system parameter setting module by the authorized users. Man-hour calculation model database is mainly used to store the mathematical model of man-hour calculation corresponding to the process template.

\section{UML Modeling of the System}

According to the overall framework of rotary bearing man-hour ration management system as shown in Fig.1, its use cases models and activity diagrams were analyzed based on UML modeling method.

\subsection{Use Cases Analysis}

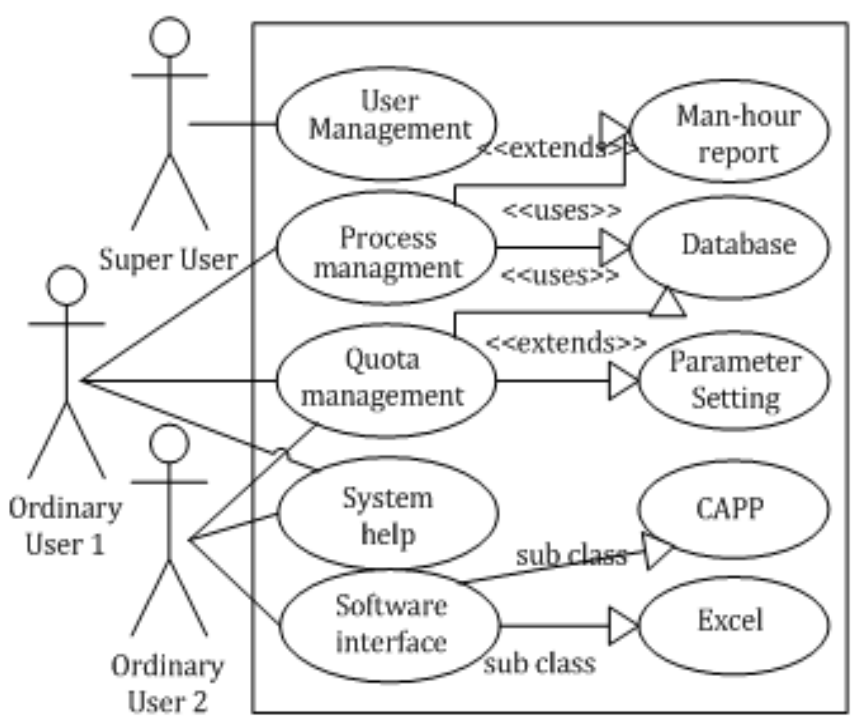

Fig. 2. The UML use cases diagram of rotary bearing man-hour ration management system.

A use case diagram depicts actors, use cases, and the relationships among them [7]. The main purpose of UML use case is to help development team to understand the functional requirements of the system by a visual way, including the relationship between roles that based on basic process and the relationship between the use cases 
in the system. According to the development requirement of rotary bearing man-hour ration management system, its UML use cases diagram is shown in Fig.2. It includes two kinds of users: super user and ordinary user. There are ten use cases, such as "user management", "process management", "quota management", "system help", "technical interface", "man-hour report", "database", parameter setting", "CAPP" and "Excel". The father cases of "process management" and "quota management" is the use case of "database". They also have expanded use cases. The "software interface" use case has two sub use cases: "CAPP" and "Excel". The super user owns all the relevant operation privileges of each use case model while ordinary users only can operate the authorized use cases models.

\subsection{System UML Activity Diagram Design}

UML activity diagram is used to describe the interaction between objects [8]. According to actual development requirements of rotary bearing man-hour ration management system, the activity diagrams were designed, as shown in Fig.3. There are three lanes in the UML activity diagrams: user interface, logical interface and database interface. The user logins the main window interface and the system will provide related operations in accordance with user's permissions. The system can retrieve the process planning information automatically according to the product parameters selected by the user. It will calculate the related man-hour according to man-hour database. And it can automatically generate man-hour report.

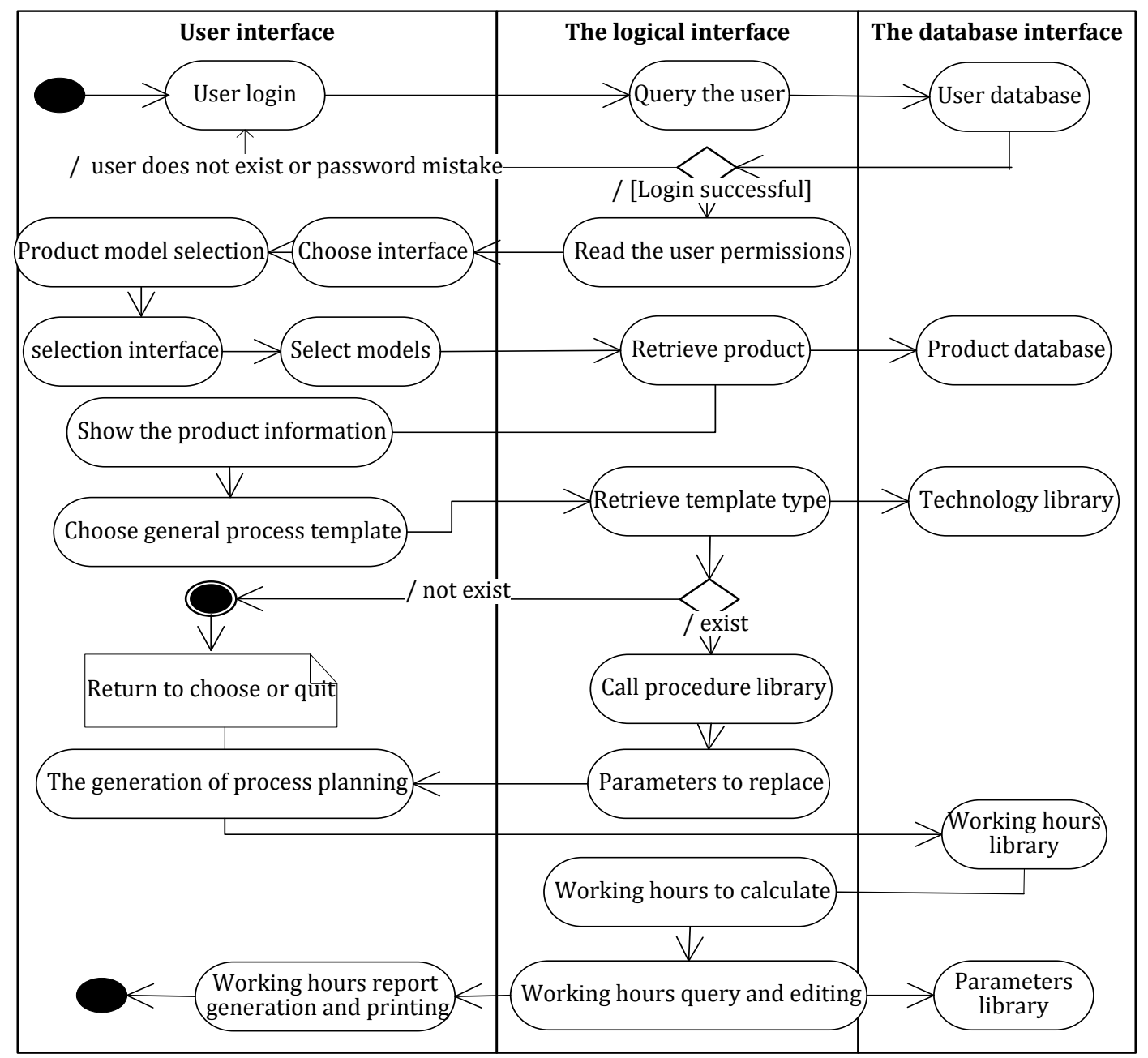

Fig. 3. System UML activity diagram design.

\section{Man-Hour Calculation Method}

Man-hour includes machining time and auxiliary time. There are mainly three kinds of calculation method of 
machining time, including experience estimation method, analogy comparison method and analytical calculation method.

\subsection{Machining Time Calculation Method}

According to the structure and process characteristics of rotary bearing products, the paper established the general process templates of rotary bearing inner and outer ring parts. The machining time was calculated by using the analytic calculation method. For example, the "rough turning" general process template of an outer ring part is shown in Fig. 4, which shows the universal process planning and process parameters.

The key of analytical calculation method is to establish machining time quota calculation model of each

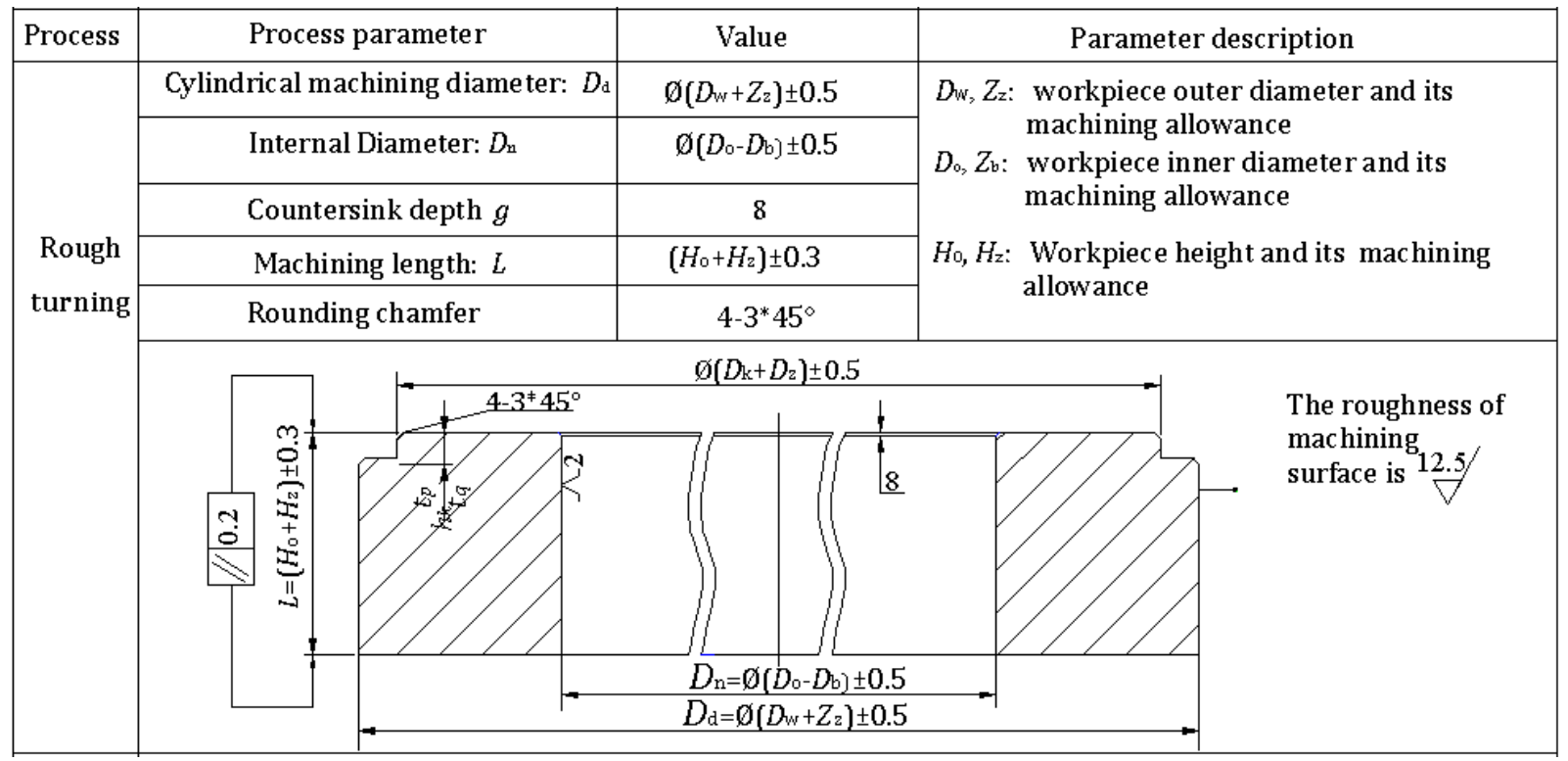

Fig. 4. The "rough turning" general process template of an outer ring part.

process steps of rotary bearing inner and outer parts. Based on general process templates of rotary bearing inner and outer ring parts, the time quota calculation models of each process steps were established, including cylinder turning, facing, chamfering, drilling, knurling, slotting internal or external gears, gear hobbing, teeth chamfering, scribing and drilling, boring with short cutter bar, boring, cylindrical grinding, face grinding, grinding inner hole, etc. In consideration of the actual processing conditions and technical requirements of rotary bearing manufacturing enterprise, the corresponding correction coefficients about machining time quota calculation model were set, including surface roughness coefficient $k$, material correction coefficient $k_{1}$, mechanic skills coefficient $k_{2}$, machine coefficient $k_{3}$, etc. According to actual cutting condition, the default values of these coefficients can be adjusted in man-hour quota module, in order to satisfy the actual cutting process requirement of the enterprise. For example, according to Ref. [9], the machining time quota calculation model of "cylindrical turning" process step can be expressed as the following.

$$
\left\{\begin{array}{l}
T=\frac{\left(0.24 \times\left[D_{\mathrm{d}}\right][L]+2040\right)}{1000}[K]\left[K_{1}\right]\left[K_{2}\right]\left[K_{3}\right] \\
D_{\mathrm{d}}=D_{w}+Z_{z} \\
L=H_{0}+H_{z}
\end{array}\right.
$$

As in (1), $T$ is machining time of "cylindrical turning" process step (min), $k$ is surface roughness coefficient, $k_{1}$ is material modification coefficient, $k_{2}$ is mechanic skills coefficient, $k_{3}$ is machine tool coefficient, $D_{\mathrm{d}}$ is cylindrical machining diameter $(\mathrm{mm}), D_{\mathrm{W}}$ is workpiece outer diameter $(\mathrm{mm}), Z_{\mathrm{z}}$ is machining allowance of workpiece outer diameter ( $\mathrm{mm}$ ), it can be adjusted according to actual situation, $L$ is machining length (mm), $H_{\mathrm{o}}$ is workpiece height(mm), $H_{z}$ is machining allowance of workpiece height (mm), it can be adjusted according to actual 
situation.

\subsection{Auxiliary Time Calculation Method}

Auxiliary time includes the preparation and end time, time for loading and unloading workpiece, layout work place time and rest and physiological needs time. It is often estimated empirically by looking up the process manual.

The preparation and the end time mainly consider two factors: the complexity of the parts and the production program. The complexity is divided into three kinds: simple, medium and complex; the production program is divided into single small batch and batch production, Through long-term production practice, enterprises has worked out the preparation and end time for the different complexity under the condition of single piece and small batch. For batch production, the preparation and end time is defined as the time under a single piece and small batch condition divided by the total production. The time of loading and unloading workpiece need to consider the parts size and the clamping way. The parts size only considers the raceway diameter of rotary bearing. The clamping way includes three-jaw chuck and four-jaw chuck. With 1000mm raceway diameter rotary bearing as standard workpiece, and the time quota of loading and unloading workpiece $t$ as a benchmark man-hour quota, the time quota of loading and unloading workpiece was established, as shown in Table.1. When four-jaw chuck is used, it is multiplied by the coefficient of $K_{\mathrm{t}}$ on the basis of the three-jaw chuck time quota, the default value of the coefficient is $K_{\mathrm{t}}=2.5$.

Table 1. The Time Quota of Loading and Unloading Workpiece

\begin{tabular}{|c|c|c|}
\hline Raceway diameter(mm) & Three-jaw chuck (min) & Four -jaw chuck (min) \\
\hline 710 & $0.75 t$ & $1.5 t$ \\
\hline 800 & $0.8 t$ & $1.8 t$ \\
\hline 900 & $0.95 t$ & $2.15 t$ \\
\hline 1000 & $t$ & $2.5 t$ \\
\hline 1120 & $1.05 t$ & $2.63 t$ \\
\hline 1250 & $1.1 t$ & $2.75 t$ \\
\hline
\end{tabular}

The time to layout work place and to rest for physiological needs is multiplied by an experience coefficient on the basis of machining time, and it can be adjusted according to the enterprise actual situation in the man-hour ration management system.

\section{Generate and print of Man-Hour Report}

Man-hour ration management system provides two types of man-hour report, one is detailed table of planning man-hour, and the other one is summary table of planning man-hour. They are defined in Visual Basic 6.0 development tool as man-hour report class in advance.

The process and man-hour information of the rotary bearing parts are read from the FlexGrid control into the man-hour report class module. When need to preview, the man-hour report class module will draw the process and man-hour information in a PictureBox control to achieve preview function. When need to print, the man-hour report class module will draw the process and man-hour information in the current default printer to print directly. The format of the man-hour reports is unified and standard.

\section{Application Case}




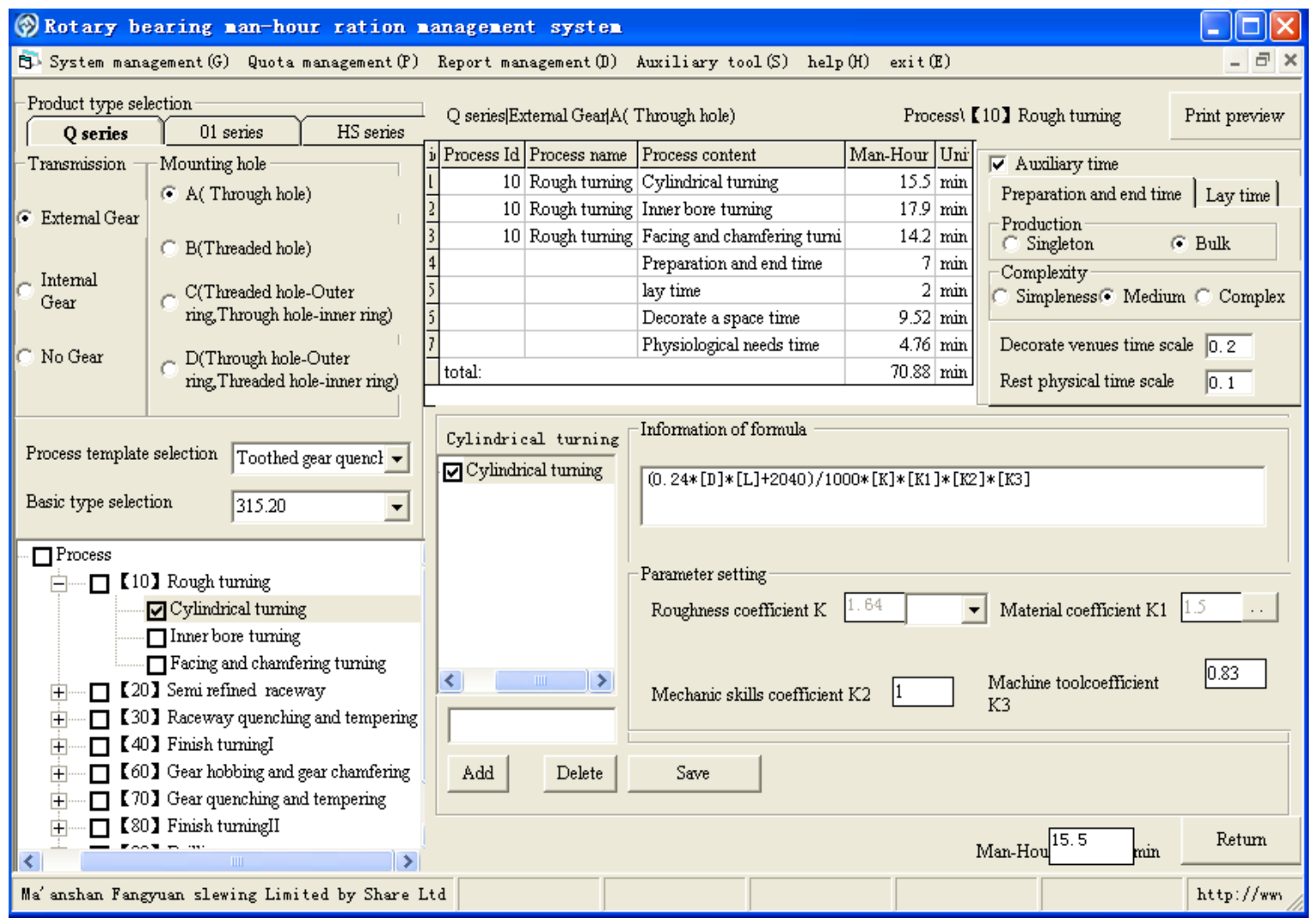

Fig. 5. The man-hour calculation and query interface of a rotary bearing outer ring parts.

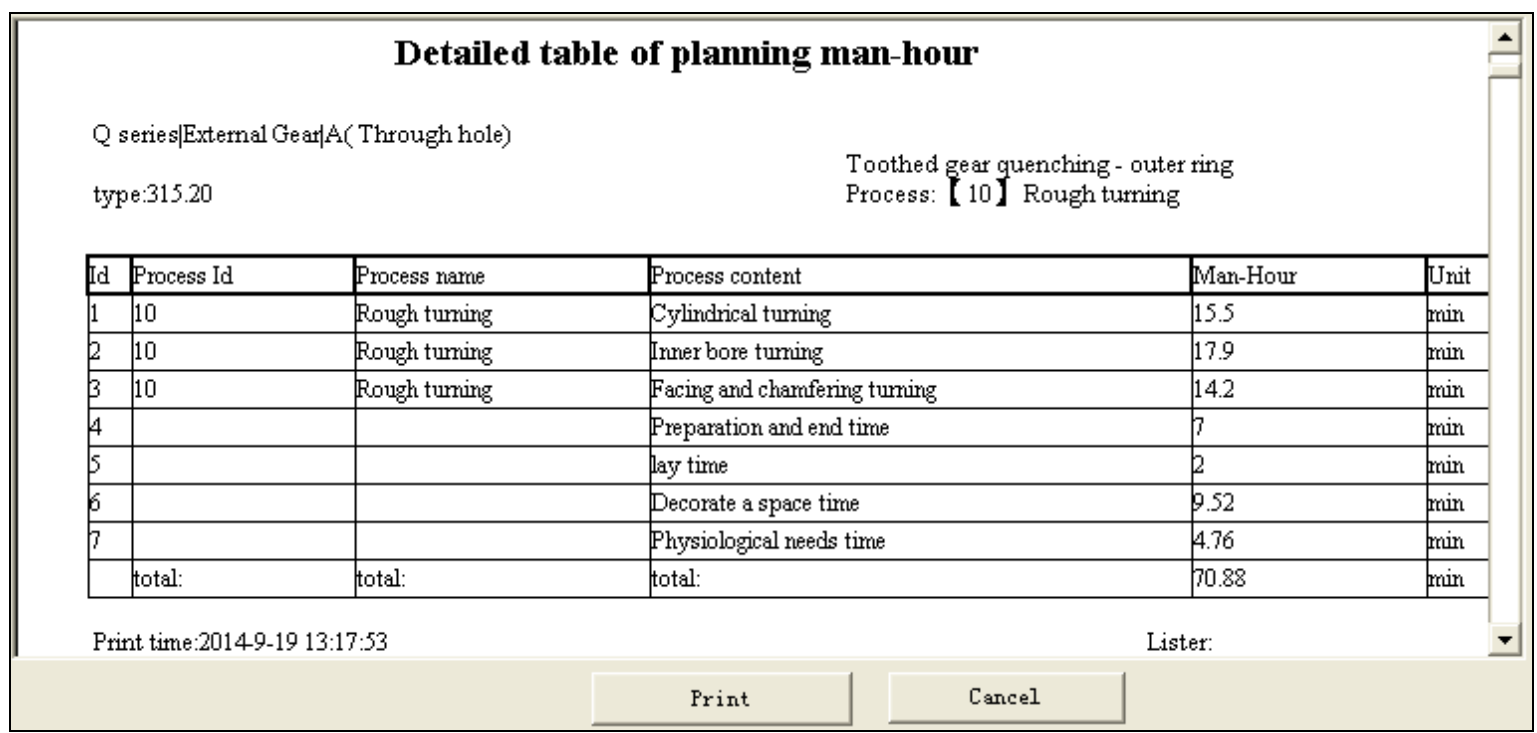

Fig. 6. The man-hour reports generation and print interface.

On the basis of the above key technologies, a man-hour ration management system about single row ball rotary bearing products was developed successfully by using Visual Basic 6.0 and SQL Sever database. Fig. 5 is the man-hour calculation and query interface of a rotary bearing outer ring parts. The upper left of the interface is the product type selection interface, including product series, transmission type, basic type, mounting holes code etc, the lower left of the interface is the process information of the selected rotary bearing product type which are retrieved from the process database. On the right side of the interface provides the function of calculation, query, edit, modify of man-hour time and automatically generate and print of man-hour reports. The man-hour reports generation and print interface is shown in Fig. 6. 


\section{Conclusion}

The rotary bearing man-hour ration management system mentioned above has been successfully applied in a rotary bearing manufacturing enterprises. Compared with the traditional method of man-hour calculation, the system improves the accuracy and efficiency of machining time quota calculation of the rotary bearing.

\section{Acknowledgment}

This work is supported by Anhui science and technology research key projects of China (No. 08010201115).

\section{References}

[1] Yang, H., \& Wu, X. (2007). Study on the man-hour calculation of mould based on parser. Equipment Manufacturing Technology, (10), 37-39.

[2] Zhai, S., \& Jiang, Z. (2012). Man-hour calculation methods of the block assembly for shipbuilding. Journal of Harbin Engineering University, 33(5), 550-555.

[3] Du, M., Huang, Y., \& Wang, X. (2006). Development of man-hour subsystem of machining in CAPP system. Journal of Machine Design, 23(1), 10-12.

[4] Wang, Y., Zhu, Y., \& Jiang, Y. (2010). Slewing rings CAPP software development. Modern Manufacturing Engineering, (10), 73-76.

[5] JB/T10839-2008. (2008). Construction Machinery and Equipment Single-Row Rotary Bearing (pp. 8-18). Beijing: Mechanical Industry Press.

[6] JB/T2300-2011. (2011). Rotary Bearing Type and Basic Parameters and Technical Requirements (pp. 5-10). Beijing: Mechanical Industry Press.

[7] Sheng, L. M., Sui, F., Li, F., Bai, L., \& Wang, L. (2009). Workflow modeling with extended UML activity diagrams and its transformation into XPDL. Computer Integrated Manufacturing Systems, 15(8), 1514-1521.

[8] Yi, D., Chen, X., \& Liu, L. (2008). Modeling of man-hour quote information management system based on UML. Control \& Automation, (3), 21-22.

[9] Hou, Z., \& Yang Wang. (1981). Formulation and Computer Calculation of Machinery Manufacturing Time Quota Standards (pp. 138-140). Beijing: Mechanical Industry Press.

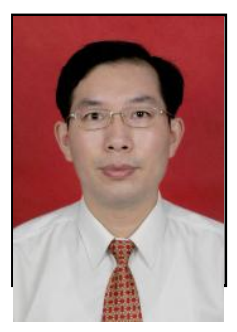

Yongming Wang was born in Jixi County, Anhui province, P. R. China in 1971. He received the master degree of mechanical engineering from Hefei University of Technology, Hefei, P. R. China in 1999, and received the Ph.D. degree of mechanical engineering from Southeast University, Nanjing, P. R. China in 2011. Now he is a Prof. of Anhui University of Technology, and his major fields of study are manufacturing information technology, robot technology.

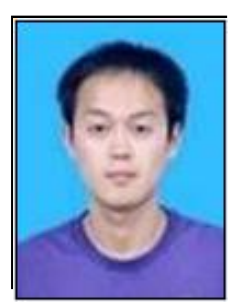

Shuai Xia was born in Liaocheng, Shandong province, P. R. China in 1987. He received the bachelor degree of mechanical engineering from Shandong University of Technology in 2012. Now he is studying in Anhui University of Technology, and his major field of study is manufacturing information technology. 